EFFECTIVENESS OF COMMUNITY BASED FITNESS AND MOBILITY EXERCISE PROGRAM (FAME) IN IMPROVING THE HEALTH RELATED QUALITY OF LIFE IN SUBJECTS WITH CHRONIC STROKE

\title{
Doss Prakash S ${ }^{* 1}$, Vijay Kumar P $^{2}$, Kowshik Reddy B ${ }^{3}$.
}

${ }^{* 1}$ Associate Professor, Department of Community Physiotherapy, MGM Institute of Physiotherapy, N-6 CIDCO, Aurangabad - 431 003, Maharashtra, India.

${ }^{2}$ Professor, Department of Musculoskeletal Physiotherapy, Navodaya College of Physiotherapy, Raichur - 584 103, Karnataka, India.

${ }^{3}$ Professor, Department of Musculoskeletal Physiotherapy, Navodaya College of Physiotherapy, Raichur - 584 103, Karnataka, India.

\section{ABSTRACT}

Background: In the rehabilitative management of persons with stroke, more efforts are emphasized to improve motor and cognitive impairments. However, assessment and health promotion of the fitness of stroke patients in a community set up and Quality of life have so far received limited attention. The goal was to determine the efficacy of community based FAME program in patients with chronic stroke.

Objectives: To examine the effects of a community-based group exercise program in improving the health related quality of life in subjects with chronic stroke.

Design:Randomized control group trial

Participants: Fifty eight chronic stroke individuals (aged 45-65 years) who were living in the community.

Intervention: Participants were randomized into experimental group ( $n=29)$ and control group $(n=29)$. The experimental group underwent a fitness and mobility exercise (FAME) program along with strengthening exercises designed to improve fittness, mobility and quality of life (1-hour sessions, three sessions/week, for 14 weeks). The control group underwent strengthening program.

Measurements:The health related quality of life was assessed by SS-QoL (Stroke Specific Quality of Life) in day zero, $8^{\text {th }}$ week and end of $14^{\text {th }}$ week.

Results:The experimental group had showed significantly more gains in Quality of Life when compared to control Group. $(p<0.001)$

Conclusion: The FAME program is feasible and beneûcial in improving the quality of life and may prevent some of the secondary complications resulting from physical inactivity in older adults living with stroke. It serves as a good model of a community-based ûtness program for preventing secondary diseases in older adults living with chronic conditions.

KEY WORDS: Stroke, health promotion, community based fitness and mobility exercise, health related quality of life,stroke specific quality of life, rehabilitation.

Address for correspondence: Dr Doss Prakash S, Associate Professor, Department of Community Physiotherapy, MGM Institute of Physiotherapy, N-6 CIDCO, Aurangabad - 431 003, Maharashtra - INDIA. Mobile : +91-98863 86726. E-Mail:dossprakashs@gmail.com

\begin{tabular}{|l|l|}
\hline Access this Article online & \multicolumn{2}{|c|}{ Journal Information } \\
\hline Quick Response code & $\begin{array}{r}\text { International Journal of Physiotherapy and Research } \\
\text { ISSN (E) 2321-1822 I ISSN (P) 2321-8975 } \\
\text { https://www.ijmhr.org/ijpr.html } \\
\text { Dol-Prefix: https://dx.doi.org/10.16965/ijpr }\end{array}$ \\
\hline
\end{tabular}




\section{INTRODUCTION}

Stroke is the second leading cause of death and a major cause of disability worldwide. Two-thirds of stroke deaths occurs in developing countries worldwide [1]. More than three fourths of these occur in Low and Middle Income Countries (LMICs) of the world [2]. Countries with large populations (like India, China, Brazil and Russia) contribute for greater numbers of deaths and disability due to stroke [3-6]. In 2001, pooled estimates for India showed that the prevalence of stroke was 203 per 100,000 population and contributing for 1.2 per cent of the total deaths (approximately 102,000 deaths) [7].The Indian Council of Medical Research (ICMR) estimates indicated that amongst the Non Communicable Diseases (NCDs), stroke contributes for 41 per cent of deaths and 72 per cent of Disability Adjusted Life Years (DALYS) [8].

Stroke is the most frequent cause of residual disability. In the rehabilitative management of persons with stroke, efforts have been made to maximize their functional recovery by optimizing motor and cognitive impairments, but promotion of the health and ûtness of stroke patients have so far received limited attention.

The Framingham study found that at 6 months following a stroke i.e, after the period of natural recovery

- $50 \%$ of stroke survivors aged 65 years or older had some hemiparesis and

- $30 \%$ were unable to walk without assistance.

Generally, the ûow of stroke rehabilitation is categorized into the acute, convalescent and chronic phases [9]. Convalescent phase rehabilitation is intensive and comprehensive rehabilitation given by a rehabilitation team [10]. With more active rehabilitation following acute phase rehabilitation, the maximum recovery of capacity, such as self-care, locomotion and communication, and early social reintegration are attempted in patients who are expected to respond to the therapeutic approach. Chronic phase rehabilitation is carried out to maintain the capacity gained through the recovery phase rehabilitation for as long as possible. In all these phases, the Health Related Quality of Life (HRQoL) is ignored in these stroke survivors, and they are more prone for depression and gloominess [11].

Due to the sedentary lifestyle associated with these limitations, the stroke survivor is at increased risk of diabetes, glucose intolerance, heart disease, depression and subsequent stroke death.This can hinder successful rehabilitation [12], and can interfere with their reintegration into the community after medical rehabilitation.

Most stroke survivors continue to live with residual physical impairments, which may promote a sedentary lifestyle and resultant secondary complications [13].Low cardio respiratory ûtness is related to poor functional performance [14] and increased risk of stroke and cardiovascular disease (CVD) $[15,16]$. Indeed, cardiac events and recurrent stroke are major occurrences in stroke survivors $[17,18]$.

Studies have shown that the incidence of stroke is increasing, particularly in older people, but the mortality rate of stroke has been declining [19], and more stroke survivors are returning home instead of going into inpatient rehabilitation programs [20]. These factors may translate into an increasing number of older adults living with a chronic stroke in the community who have not attained optimal functional recovery and are at risk of developing secondary complications due to physical inactivity.

There has been an increasing recognition of the importance of health promotion for people with disabilities. One of the key components of health promotion for people with disabilities is "the prevention of health complications, addressing their mood swings / depression and further disabling conditions." According to a proposed conceptual model of health promotion, community-based ûtness programs play one important role in achieving this objective [21].

Considering that physical inactivity in older adults with chronic stroke could lead to devastating secondary health complications, an accessible and multidimensional ûtness program is urgently needed, but most exercise programs proposed for chronic stroke, are not community based and have addressed only one or two of the impaired domains [22].

In this study, our aim was to analyze the effectiveness of community based Fitness And Mobility Exercises and quality of life in subjects 
with chronic stroke.

\section{MATERIALS AND METHODS}

The stroke survivors' data was collected from 1050-bedded tertiary care teaching hospital in Raichur district of Karnataka, India. Total 117 stroke survivor's data for three years (2009 to 2011) were extracted from the medical records department of the tertiary care teaching hospital, in which 60 subjects with age group between 45-65 years were selected through block randomization technique. Since, the study is true experimental in nature, Randomized sampling technique was adopted and the subjects were assigned in two groups.

30 subjects $(n=30)$ were allocated in Experimental group (Group $-A$ ) in which they received strengthening programs and Fitness \& Mobility Exercise (FAME) program. 30 subjects $(n=30)$ were allocated in Control group (Group - B) in which they received strengthening programs only. However, one subject from experimental group was dropped out from the study after $8^{\text {th }}$ week due to second stroke attack and one subject from control group was dropped out from the study before $8^{\text {th }}$ week due to sudden cardiac illness. Hence the total sample size who completed the study was $58 .(n=58)$

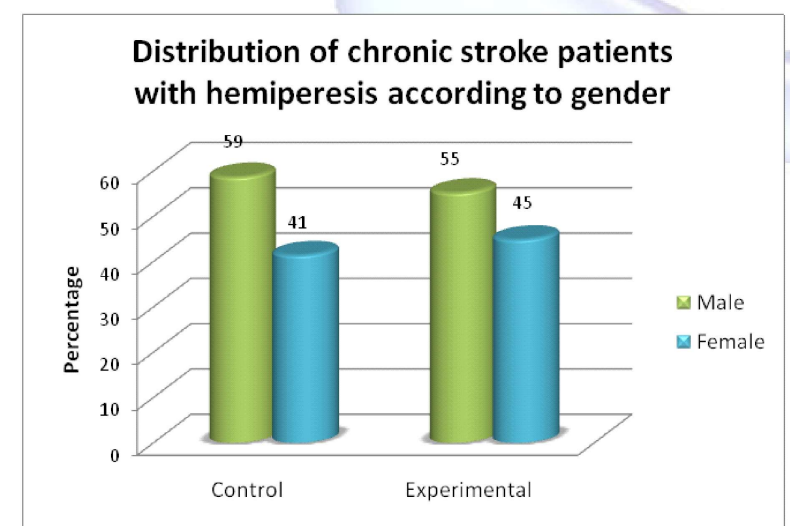

Mean age (years) of chronic stroke patients with hemiperesis

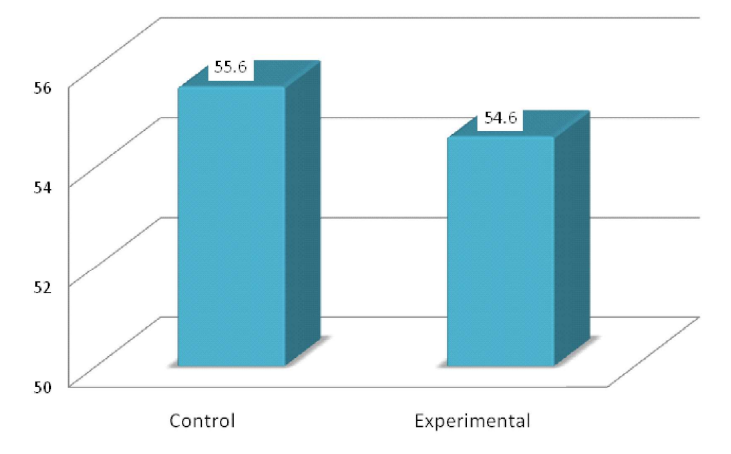

The Health related quality of life (HRQoL) were assessed for all the subjects as baseline data before the study in both the groups by this variable - Stroke Specific Quality of Life Scale (SS-QoL) respectively.

\section{Stroke Specific Quality of Life Scale (SS-QoL):}

The subjects are interviewed with Stroke Specific Quality of Life Scale (SS-QoL) in 12 commonly affected domains: energy, family roles, language, mobility, mood, personality, self-care, social roles, thinking, upper extremity function, vision, and work/productivity. Each domain had many sub items and the scoring was done separately with different keys.

Procedure: After obtaining informed consent and baseline data, a brief explanation of the treatment procedure was given to both the group subjects. Intervention group subjects received Strengthening exercise \& Fitness and Mobility Exercise program and Control group subjects received strengthening program alone. The intervention exercises for both the groups were demonstrated to the patients clearly at their residence and an exercise leaflet with followup chart was given to all the subjects.

The experimental and control groups underwent the exercise program for 14 weeks (1-hour session, three sessions per week) in their residence. A treatment check list chart was given to each subject, with instructions to record the date, time of the exercise and a weekly follow up to their residence was made to ensure their regular practice sessions. The therapeutic exercises was preceded by warm up period and followed by cool down period.

Fitness and Mobility Exercise program(FAME)

\section{Cardio respiratory ûtness and mobility}

- Brisk walking in the available open area near by their residence

- Sit-to-stand: progressed by reducing the height of chair

- Alternate stepping onto low risers: progressed by increasing the height of the stepper, reducing arm support, or both

Duration and Progression: 10 minutes initially, with increment of 5 minutes every week, up to 30 minutes of continuous exercise as tolerated 


\section{Mobility}

- Walking in different directions \& Tandem walking

- Walking through an obstacle course

- Sudden stops and turns during walking

- Walking on different surfaces (carpet, foam)

- Standing with one foot in front of the other

- Kicking ball with either foot

Progressed by reducing arm support, by increasing speed of movement, or both

\section{Leg muscle strength}

- Partial squats: progressed by increasing movement magnitude

- Toe rises: progressed from bilateral to unilateral rises on either side

Progressed by using De Lormes technique, reducing arm support, or both. The progression was made in follow up visits.

Group B received strengthening program for upper and lower extremity program.

Shoulder muscle strength:Resisted exercises (movements: shoulder ûexion, abduction, extension, external rotation) by therabands. Progression was be made by De Lormes technique during each follow up visits

Elbow/wrist muscle strength and range of motion:Sandbag / wrist cuff weight exercises. Progression was be made by De Lormes technique during each follow up visits. Passive or self-assisted range of motion to paralyzed joints by the care givers

\section{Upper extremity weight-bearing}

\section{Hand activities}

1. Hand muscle strengthening exercises using mud and grippers

2. Picking up objects of various sizes and shapes using different sizes and textures of stones

\section{Leg muscle strength}

- Partial squats: progressed by increasing movement magnitude

- Toe rises: progressed from bilateral to unilateral rises on either side

Progressed by using De Lormes technique, reducing arm support, or both.

The Health related quality of life (HRQOL) level was also assessed by Stroke Specific Quality of Life Scale (SS-QoL) in both the groups at the end of $8^{\text {th }}$ week and at the end of treatment (14 ${ }^{\text {th }}$ week)

As the trial progressed, exercise intensity and duration were increased to both the group subjects as tolerated.

Statistical Test: The obtained data was analyzed and compared with Pre \& post test score of the both experimental and control group by using $f$ value, statistical paired ' $\mathrm{t}$ ' $\&$ unpaired ' $\mathrm{t}$ ' test. Comparison between Intragroup was done by paired " $\mathrm{t}$ " test and inter group comparison was be done by unpaired' $t$ ' test. The data were examined for normality by Kolmogorov and Smirnov test. Wherever the data was not normally distributed, nonparametric test was used. Data expressed as mean \pm SD. Baseline variables between the two groups were compared using chi-square for categorical variables. Repeated measures of ANOVA were used within groups for over of period followed by post hoc test Dunnett Multiple Comparisons Test. A two tailed $p$-value less than 0.05 was considered as significant. Data analysis was done using Minitab version 14.0.

\section{RESULTS}

Participants $(n=58)$ were 55.1 years old with chronic stroke and hemiperesis.

Table 1:Basic characteristics of the subjects (Mean $\pm S D$ ).

\begin{tabular}{|c|c|c|}
\hline Group & Age (years) & $\begin{array}{c}\text { Male / } \\
\text { Female }\end{array}$ \\
\hline Control $(\mathbf{n = 2 9 )}$ & $55.6 \pm 5.9$ & $17-12$ \\
\hline Experimental $(\mathbf{n = 2 9 )}$ & $54.6 \pm 5.4$ & $16 / 13$ \\
\hline p-value & $\mathrm{P}=0.52$ & $\mathrm{P}=0.99$ \\
\hline
\end{tabular}

Table 1 shows baseline characteristic of all participants. 60 participants were included in the study. However two participants from experimental and control group were excluded from the study because of second stroke attack and sudden cardiovascular illness. Hence twenty nine $(n=29)$ participants with mean age of $55.56 \pm 5.9$ years completed the study in Control group (strengthening exercises group) and twenty nine $(n=29)$ participants with mean age of $54.6 \pm 5.4$ years completed the study in Experimental group (fitness and mobility exercise and strengthening exercises group). 
Doss Prakash S, Vijay Kumar P, Kowshik Reddy B. EFFECTIVENESS OF COMMUNITY BASED FITNESS AND MOBILITY EXERCISE PROGRAM (FAME) IN IMPROVING THE HEALTH RELATED QUALITY OF LIFE IN SUBJECTS WITH CHRONIC STROKE.

Table 2: Efficacy of FAME and strengthening exercise and SS-QoL in chronic stroke patients.

\begin{tabular}{|c|c|c|c|c|c|c|c|}
\hline SS-QoL & $\mathbf{0}$ day & $\mathbf{8}^{\text {th }}$ week & $\mathbf{1 4}^{\text {th }}$ week & $\begin{array}{c}\text { Mean difference (SD) } \\
{\left[\text { Baseline-8 }{ }^{\text {th }} \text { week] }\right.}\end{array}$ & $\begin{array}{c}\text { Mean difference } \\
\text { (SD) [Baseline-14 } \\
\text { week] }\end{array}$ & F-value & $p$-value \\
\hline Control & $110.34 \pm 10.9$ & $130.41 \pm 7.8^{* *}$ & $150.9 \pm 7.9^{* *}$ & $20.07 \pm 5.03$ & $40.5 \pm 7.04$ & 777.4 & $P<0.0001$ \\
\hline Experimental & $112.4 \pm 11.6$ & $139.2 \pm 10.5^{* *}$ & $172.7 \pm 8.3^{* *}$ & $26.8 \pm 5.6$ & $60.3 \pm 8.54$ & 1101.7 & $P<0.0001$ \\
\hline
\end{tabular}

$* p<0.05, * * p<0.01$ compared to baseline ( 0 day) after ANOVA followed by Dunnett Multiple Comparisons Test

Table3a: Comparison of SS-QoL parameter between control and experimental groups at baseline ( 0 day ).

\begin{tabular}{|c|c|c|c|c|c|c|}
\hline Parameter & Control & Experimental & $\begin{array}{c}\text { Mean } \\
\text { difference }\end{array}$ & $\begin{array}{c}95 \% \mathrm{Cl} \\
\text { difference }\end{array}$ & t-value & p-value \\
\hline SS-QoL & $110.34 \pm 10.9$ & $112.4 \pm 11.6$ & 2.03 & $-3.87-7.94$ & 0.69 & $\mathrm{P}=0.49$ \\
\hline
\end{tabular}

Table 3 data shows intergroup comparison of Table 3 data shows intergroup comparison of SS-QoL at 0 day (baseline data). The mean and SD of SS-QoL in control group at baseline was $110.34 \pm 10.9$. The mean and SD of SS-QoL in experimental group was $112.4 \pm$ 11.6.The obtained $t$ value for SS-QoL was 0.69 with $(-3.87-7.94) \mathrm{Cl}$ difference. Statistical significance difference was not found between the groups $(p=0.49)$. Hence the homogeneity of the sample in pre experiment (Baseline data) was obtained.

SS-QoL at $8^{\text {th }}$ week. The mean and SD of SS-QoL in control and experimental group at $8^{\text {th }}$ week are $130.41 \pm 7.8$ and $139.2 \pm 10.5$ respectively. The obtained $t$ value for SS-QoL was 3.63. Statistical significance difference was found between the groups $(p<0.0006)$. This shows that there was a significant difference between the groups among SS-QoL on $8^{\text {th }}$ week of intervention.

Table3b: Comparison of SS-QoL between control and experimental groups at $8^{\text {th }}$ week.

\begin{tabular}{|c|c|c|c|c|c|c|}
\hline Parameters & Control & Experimental & $\begin{array}{c}\text { Mean } \\
\text { difference }\end{array}$ & $\begin{array}{c}95 \% \mathrm{Cl} \\
\text { difference }\end{array}$ & t-value & p-value \\
\hline SS-QoL & $130.41 \pm 7.8$ & $139.2 \pm 10.5$ & 8.79 & $3.93-13.65$ & 3.63 & $\mathrm{P}<0.0006$ \\
\hline
\end{tabular}

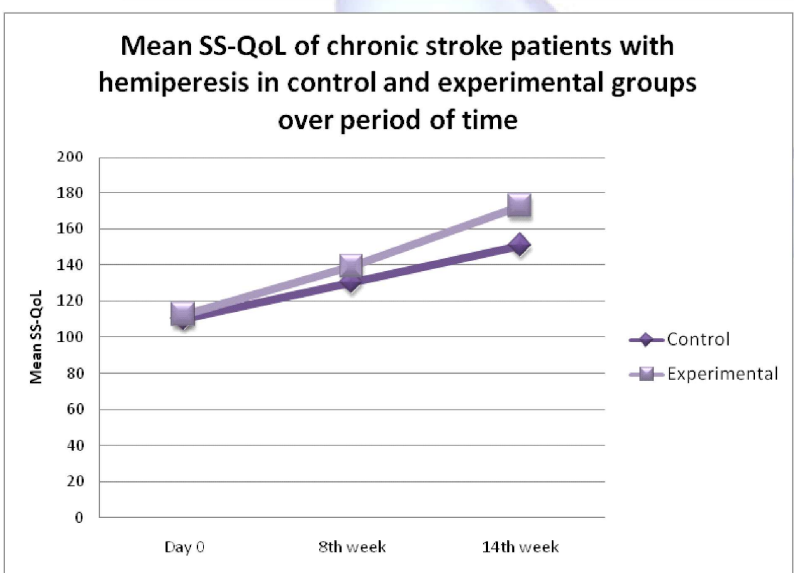

Table 4 data shows intergroup comparison of SS-QoL at $14^{\text {th }}$ week. The mean and SD of SSQoL in control and experimental group at $14^{\text {th }}$ week are $150.9 \pm 7.9$ and $172.7 \pm 8.3$ respectively. The obtained $t$ value for SS-QoL was 10.2. Statistical significance difference was found between the groups $(p<0.0001)$. This shows that there was a significant difference between the groups in SS-QoL on $14^{\text {th }}$ week of intervention.

Table4: Comparison of parameters between control and experimental groups at $14^{\text {th }}$ week.

\begin{tabular}{|c|c|c|c|c|c|c|}
\hline Parameters & Control & Experimental & $\begin{array}{c}\text { Mean } \\
\text { difference }\end{array}$ & $\begin{array}{c}95 \% \mathrm{Cl} \\
\text { difference }\end{array}$ & t-value & p-value \\
\hline SS-QoL & $150.9 \pm 7.9$ & $172.7 \pm 8.3$ & 21.83 & $17.54-26.1$ & 10.2 & $\mathrm{P}<0.0001$ \\
\hline
\end{tabular}

DISCUSSION

The community dwelling chronic stroke patient's fitness are more prone to depression due to the consequence of physical inactivity and lack of accessible and appropriate and encouraging community-based exercise programs. Further rejection from family, society and sometimes over protection by the family members leads to considerable depression levels subsequently affecting the quality of life. Pettersen $R$ et al (2002) found that after rehabilitation, $62 \%$ of stroke patients were still dependent regarding daily living activities (ADL) and $32 \%$ were inactive regarding Instrumental ADLs at chronic post stroke stage. 
In our study, there was a significant level of improvements in Quality of Life in experimental group subjects when compared with control group subjects after the end of $8^{\text {th }}$ week and $14^{\text {th }}$ week. The quality of life in chronic stroke subjects was very much affected in both the groups with mean SS-QoL score of 112.4 in experimental group and the mean SS-QoL score of 110.34 in control group. At the end of the 14 week study, the mean SS-QoL score of experimental group was 172.7 and the mean SS-QoL score of control group was 150.9.

The statistical analysis shows that there was a homogeneity among the groups before the intervention $(p>0.05)$ with all the three measures. When compared to the baseline data with the $8^{\text {th }}$ week and $14^{\text {th }}$ week for both control and experimental group there was a significant difference in both the groups in SS-QoL. $(P<0.001)$

Statistical significance difference was not found between the groups in baseline data of SS-QoL since the $p$ values were equal. Whereas there was a significant difference between the groups in SS-QoL $(p<0.0006)$ on $8^{\text {th }}$ week of intervention. Further $14^{\text {th }}$ week of intervention showed significant difference between the groups in SS-QoL $((p<0.0001)$

Community involvement of stoke subjects leads to ease the pressure from family members considerably. Further, the subjects active participation in the community reduces the depression level thereby improves the quality of life. Although stroke is a major problem, the best method for measuring the outcome of stroke is not clear, partly due to the heterogeneity of stroke signs and symptoms. The Stroke Specific Quality of Life Measure (SS-QoL) instrument is the latest of the tools for post-strokespecific QOL scales. Several studies have shown that by far the largest part of the patients experience and report a decline in QOL after stroke, and this even applies to persons who have suffered only a minor stroke. There are a number of factors which seem to be contributing towards a decline in QOL of stroke patients. Advanced age, the severity of motor impairmentor paralysis, lack of perceived social supports, inability to return to work, supratentorial lesion locations, impaired cognition, and the presence of comorbid health problems have been associated with a decline in QOL and should be taken into account when making an analysis of stroke results. Several authors have reported a strong association between physical disability, dependency in activities of daily living and QOL. Ss-QoL was developed to deal with the items which are most pertinent to stroke patients and are likely to become the more suitable measurement of post stroke QOL also because of the greater ability to pinpoint significant changes.

\section{CONCLUSION}

Stroke is the second leading cause of death and it creates enormous impact in fitness and mobility. This in turn leads to severe emotional disturbances causing depression and subsequently affecting the quality of life. Although stroke causes problems across multiple systems, including motor control, upper-extremity function, balance, gait, and endurance, most stroke rehabilitation treatment programs focus on only 1 or 2 dimensions of stroke impairments or functions. Stroke patients experience lifetime disabilities and need care over a long period of time to cope with the consequences of their stroke. The quality of life dimension is being neglected by the health care providers. There has been an increasing recognition of the importance of health promotion for people with disabilities and studying their quality of life. According to a proposed conceptual model of health promotion, community-based ûtness programs play one important role in achieving this objective.

There is no single model for rehabilitation and study in the community for people pertaining to the quality of life among stroke survivors as models differ in their timing, duration of service, therapy and team content. Ourstudy was to find the efficacy of FAME in chronic stroke subjects. Chronic stroke subjects living in the community were examined and randomized in experimental and control groups. Experimental group received community based FAME \& Strengthening program for a period of 14 weeks with 3 times per week. Control group subjects received Strengthening program for a period of 14 weeks with 3 times per week. Each subject quality of 
life scores are assessed by SS-QoL in Day $0,8^{\text {th }}$ week and $14^{\text {th }}$ week. The statistical result suggested that FAME Program in experimental group showed better results in SS-QoL with $t$ value of 0.69 on day $0,3.63$ on $8^{\text {th }}$ week and 10.2 on $14^{\text {th }}$ week and had significant difference $(p<0.001)$ compared to control group.Thus the study concludes that community based FAME programs in chronic stroke leads to improvementin their Quality of Life.

The challenge for health planners is to devise ways to implement ongoing programs that are accessible and affordable.

Limitations: The results are generalizable to a selected group of community-dwelling individuals with chronic stroke only. The sample size for each group was less and dropouts further decreased the sample size. No attempts were made to help participants to develop exercise habits on a long-term basis. It is not known whether the participants continued to exercise after the termination of the program.

\section{Recommendations:}

A larger sample size and long-term follow up would be required to determine the long-term beneûts and adherence to an ongoing exercise program. It would also be interesting to determine whether the FAME program would reduce the actual risk of cardiac events, osteoporosis, or fractures. Nevertheless, the positive outcomes from this trial justify a multicentered trial to further study the efficacy and cost-effectiveness of the FAME program in improving the Quality of life.

\section{Conflicts of interest: None}

\section{REFERENCES}

[1]. Warlow C, Sudlow C, Dennis M, Warlow C, Sudlow C, Dennis M, et al. Stroke. Lancet 2003; 362 : 121124.

[2]. Feigin VL. Stroke in developing countries: can the epidemic be stopped and outcomes improved. Lancet Neurol 2007; 6 : 94-7.

[3]. Feigin VL. Stroke epidemiology in developing world. Lancet 2005; $365:$ 2160-1.

[4]. World Health Organization. The economic impact of chronic diseases in preventing chronic diseases: a vital investment. World Health Organization, Geneva; 2005.

[5]. Liu M, Wu B, Wang W, Lee L, Zhang S, Kong L. Stroke in China: Epidemiology, prevention and management strategies. Lancet Neurol 2007; 8 : 456-64.
[6]. Dalal P, Bhattacharjee M, , Bhat P. UN Millennium development goals: Can we halt the stroke epidemic in India. Ann Indian Acad Neurol 2007; 10 : 130-6.

[7]. Anand K, Chowdury D, Singh KB, Pandav CS, Kapoor SK. Estimation of mortality and morbidity due to strokes in India. Neuroepidemiology 2001; 20 : 20811.

[8]. Indian Council for Medical Research. Stroke. In: Assessment of the burden of non communicable diseases: Final project report. New Delhi: Indian Council of Medical Research; 2004. p. 18-22

[9]. Izumi S, Ishida A. [Rehabilitation in acute phase Evaluation and training for ambulation]. The Journal of the Japan Medical Association 2001;125:S272-S284.

[10]. Hase K, Chino N. [Rehabilitation in convalescent phase].The Journal of the Japan Medical Association 2001;125: S285-S298.

[11]. Takaoka T, Ito T. [Rehabilitation in chronic phase]. The Journal of the Japan Medical Association 2001;125:S299-S304.

[12]. Halar EM, Bell KR: Rehabilitation's relationship to inactivity.In: Kottke FJ, Lehmann JF, eds, Krusen's Handbook of Physical Medicine and Rehabilitation, 4th Ed, Philadelphia, WB Saunders, 1990; 11131133

[13]. Jorgensen HS, Nakayama H, Raaschou HO et al. Stroke. Neurologic and functional recovery the Copenhagen Study. Phys Med Rehabil Clin North Am 1999;10:887-906.

[14]. Binder EF, Birge SJ, Spina R et al. Peak aerobic power is an important component of physical performance in older women. J Gerontol A Biol SciMed Sci1999;54A:M353-M356.

[15]. Rogers MA, Yamamoto C, Hagberg JM et al. The effects of 7 years of intense exercise training on patients with coronary artery disease. J Am Coll Cardiol1987;10:32-326.

[16]. Kurl S, Laukanen JA, Rauramaa R et al. Cardiorespiratory ûtness and the risk for stroke in men. Arch Intern Med 2003;163:1682-1688.

[17]. Roth EJ. Heart disease in patients with stroke. Incidence, impact, and implications for rehabilitation. Part I. classiûcation and prevalence. Arch PhysMedRehabil1993;74:752-760.

[18]. Hardie K, Hankey GJ, Jamrozik K et al. Ten-year risk of ûrst recurrent stroke and disability after ûrstever stroke in the Perth Community Stroke Study. Stroke 2004;35:731-735.

[19]. Feigin VL, Lawes CM, Bennett DA et al. Stroke epidemiology. A review of population-based studies of incidence, prevalence, and case-fatality in the late 20th century. Lancet Neurol 2003;2:43-53

[20]. Mayo NE, Wood-Dauphinee S, Ahmed S et al. Disablement following stroke.DisabilityRehabil 1999;21:258-268

[21]. Rimmer JH. Health promotion for people with disabilities: The emerging paradigm shift from disability prevention to prevention of secondary conditions. Phys Ther1999;79:495-502.

[22]. Chu KS, Eng JJ, Dawson AS et al. A randomized controlled trial of water-based exercise for cardiovascular ûtness in individuals with chronic stroke. Arch Phys Med Rehabil2004;85:870-874. 